\title{
《Research Note»
}

\section{Egg Production, Egg Quality, Blood Profiles, Cecal Microflora, and Excreta Noxious Gas Emission in Laying Hens Fed with Fenugreek (Trigonella foenum-graecum L.) Seed Extract}

\author{
Jae-Hong Park, Yong-Min Kim and In-Ho Kim \\ Department of Animal Resource and Science, Dankook University, Cheonan, 31116, Republic of Korea
}

\begin{abstract}
This study was designed to investigate the effects of dietary fenugreek seed extract (FSE) supplementation on egg production, egg quality, blood profiles, cecal microflora, and excreta noxious gas emission in laying hens. A total of 384 laying hens (26-weeks old, Hyline-brown) were fed three different levels of FSE (0, 0.05, and $0.1 \%)$ in a cornsoybean diet for 6 weeks. The inclusion of FSE in the laying hen diet did not affect egg production, feed intake, or feed conversion among treatments; however, egg weight, eggshell breaking strength, eggshell thickness, and yolk color increased in FSE-fed groups (linear, $P<0.05$ ). Supplemental FSE decreased the serum total cholesterol concentration, whereas the HDL-cholesterol concentration increased in the FSE fed-groups (linear, $P<0.05$ ). FSE led to an increase in cecal Lactobacillus number (linear, $P<0.05$ ), and a decrease in Escherichia coli number (quadratic, $P$ $<0.05$ ) and excreta ammonia gas emission (linear, $P<0.05$ ). These results suggest that the addition of FSE does not increase egg production, but may affect egg quality, serum total- and HDL-cholesterol concentration, and cecal microflora. FSE also decreased ammonia gas emission in laying hen excreta.
\end{abstract}

Key words: ammonia gas, cholesterol, eggshell, egg weight, intestinal microbiota

J. Poult. Sci., 55: 47-53, 2018

\section{Introduction}

Phytogenic feed additives (PFA) have attracted a lot of attention in recent years. When used in diets, these substances exhibit antioxidative properties and antimicrobial activity, improve nutrient absorption, and could ultimately improve animal performance (Hernandez et al., 2004; Khalaji et al., 2011; Park et al., 2014). PFA are less toxic, have fewer side effects, and are residue-free compared with synthetic feed additives, and are thought to be ideal feed additives in animal production (Hashemi et al., 2008). Therefore, many phytogenic compounds have been recommended for use as feed additives.

Fenugreek (Trigonella foenum-graecum L) belongs to the Leguminosae family and is cultivated predominantly in India, West Asia, the Mediterranean, North Africa, and Canada (Kaviarasan et al., 2007). The seeds are generally used for condiments in various food preparations, are regarded to have great nutritive value and restorative properties, and have been used in folk medicine for centuries for

Received: January 16, 2017, Accepted: May 2, 2017

Released Online Advance Publication: July 25, 2017

Correspondence: In-Ho Kim, Department of Animal Resource and Science, Dankook University, Cheonan, 31116, Republic of Korea.

(E-mail: inhokim@dankook.ac.kr) their hypoglycemic, anthelmintic, antibacterial, antiinflammatory, antipyretic, and antimicrobial properties (Vats et al., 2002; Bash et al., 2003; Vyas et al., 2008). The major active components of fenugreek seeds are 4-hydroxyisoleucine, trigonelline, galactomannan with flavonoids, carotenoids, coumarins, and saponins, which confer pharmacological activity and beneficial effects (Udayasekhara and Sharma, 1987; Basch et al., 2003).

Recently, the modes of PFA action in vivo, including aromatic plants, plant extracts, their single active components, or their blended additives, have been investigated in several studies (Yan et al., 2011; Amouzmehr et al., 2012; Park et al., 2014; Park et al., 2015). However, in laying hens, a comparatively small number of studies have investigated the effects of fenugreek seed on production performance and egg quality. Therefore, in this study, an attempt was made to evaluate the fenugreek seed as natural growth promoter in laying hen diets. The evaluation included biochemical changes in egg production, egg quality, blood profiles, cecal microflora, and excreta noxious gas emission.

\section{Materials and Methods}

\section{Ethical Considerations}

The experimental protocols describing the management and care of animals were reviewed and approved by the 
Animal Care and Use Committee of Dankook University.

\section{Experimental Design, Animals, and Housing}

A total of 384, 26-week-old (Hyline-brown) laying hens were used in this 6 -week trial. Laying hens were randomly assigned to one of three treatments with eight replicates (16 hens/replicate). The experimental treatments were: control, basal diet (FSE 0\%); fenugreek seed extract (FSE) $0.05 \%$, basal diet + 0.05\% FSE; FSE 0.1\%, basal diet + 0.1\% FSE. The FSE used in our study was Nutrifen ${ }^{\circledR}$ (Emerald Seed Products Ltd., Avonlea, Canada), which contains $\geq 15.0$ $\mathrm{mg} / \mathrm{g}$ saponin. Nutrifen ${ }^{\circledR}$ was composed of $3584 \mathrm{kcal} / \mathrm{kg}$ ME, $10.4 \%$ moisture, $28.0 \%$ CP, $9.9 \%$ crude fiber, $10.4 \%$ crude fat, and $4.6 \%$ crude ash. It also contained macrominerals as follows; $0.34 \%$ calcium, $0.28 \%$ sulfur, $0.74 \%$ phosphorus, $0.26 \%$ magnesium, $36.2 \mathrm{mg} / \mathrm{kg}$ zinc, $21.4 \mathrm{mg} / \mathrm{kg}$ manganese, and $36.2 \mathrm{mg} / \mathrm{kg}$ iron. Laying hens were provided ad libitum access to water and feed. All the diets were formulated in mash form to meet or exceed the NRC (1994) nutrition requirement (Table 1). Treatment additives were included in the diet by replacing the same amount of corn. Laying hens were allowed to adjust to the environment for 5 days prior to beginning the feeding trial, during which they were fed a basal diet. They were raised in an ambient-

Table 1. Formula and chemical composition of basal diet (as-fed basis)

\begin{tabular}{lc}
\hline \multicolumn{1}{c}{ Item } & $(\%)$ \\
\hline Ingredients & \\
Corn & 50.40 \\
Soybean meal (CP 46\%) & 18.70 \\
Wheat grain & 10.00 \\
Corn gluten meal & 2.00 \\
Wheat bran & 5.00 \\
Animal fat & 4.40 \\
Limestone & 7.50 \\
Dicalcium phosphate (P 18\%) & 1.40 \\
Salt & 0.30 \\
DL-Met (50\%) & 0.10 \\
Vitamin premix ${ }^{1}$ & 0.10 \\
Trace mineral premix ${ }^{2}$ & 0.10 \\
Total & 100 \\
\hline Calculated values & \\
ME (kcal/kg) & 2,904 \\
CP (\%) & 15.02 \\
Lys (\%) & 0.78 \\
Met + Cys (\%) & 0.65 \\
Ca (\%) & 3.25 \\
P (\%) & 0.61 \\
\hline Pris & \\
\hline
\end{tabular}

${ }^{1}$ Provided per kilogram of premix: 125,000 IU vitamin A; 2,500 IU vitamin $\mathrm{D}_{3} ; 10 \mathrm{mg}$ vitamin $\mathrm{E} ; 2 \mathrm{mg}$ vitamin $\mathrm{K}_{3} ; 1 \mathrm{mg}$ vitamin $\mathrm{B}_{1}$; $5 \mathrm{mg}$ vitamin $\mathrm{B}_{2} ; 1 \mathrm{mg}$ vitamin $\mathrm{B}_{6} ; 15 \mathrm{mg}$ vitamin $\mathrm{B}_{12} ; 500 \mathrm{mg}$ folic acid; $35,000 \mathrm{mg}$ niacin; $10,000 \mathrm{mg}$ Ca-Pantothenate and 50 mg biotin.

${ }^{2}$ Provided per $\mathrm{Kg}$ of diet: $8 \mathrm{mg} \mathrm{Mn} \mathrm{(as} \mathrm{MnO}_{2}$ ); $60 \mathrm{mg} \mathrm{Zn} \mathrm{(as}$ $\left.\mathrm{ZnSO}_{4}\right) ; 5 \mathrm{mg} \mathrm{Cu}\left(\right.$ as $\left.\mathrm{CuSO}_{4} \cdot 5 \mathrm{H}_{2} \mathrm{O}\right) ; 40 \mathrm{mg} \mathrm{Fe}\left(\right.$ as $\mathrm{FeSO}_{4} \cdot 7 \mathrm{H}_{2} \mathrm{O}$ ); $0.3 \mathrm{mg} \mathrm{Co}\left(\right.$ as $\mathrm{CoSO}_{4} \cdot 5 \mathrm{H}_{2} \mathrm{O}$ ); $1.5 \mathrm{mg} \mathrm{I}$ (as KI), and $0.15 \mathrm{mg} \mathrm{Se}$ (as $\left.\mathrm{Na}_{2} \mathrm{SeO}_{3} \cdot 5 \mathrm{H}_{2} \mathrm{O}\right)$. regulated house, in which the temperature was maintained below $23^{\circ} \mathrm{C}$ and the light regime was set on a 16:8-light: dark cycle throughout the entire experiment. Birds were individually reared in adjacent steel cages fitted with a nipple drinker, feeder, and an egg collecting plate.

\section{Laying Production, Performance, and Egg Quality}

The hen-day egg production and egg weights were recorded daily, while feed consumption was measured weekly. The feed conversion ratio was calculated as the feed consumption per hen divided by egg weight per day per hen. For each treatment, 40 normal eggs (five eggs/cage) were collected randomly at 32 weeks and used to determine the egg quality. Eggshell color scores were determined using an eggshell color fan on a $1-15$ scale $(1=$ light to $15=$ dark brown) by a single trained evaluator. Haugh units, albumen height, and yolk color were determined, using an egg multi tester (Touhoku Rhythm Co., Ltd., Tokyo, Japan). Eggshell breaking strength was evaluated, using an Eggshell force gauge, model II (Robotmation Co., Ltd., Tokyo, Japan), and eggshell thickness was measured, using a dial pipe gauge (Ozaki Mfg. Co., Ltd., Tokyo, Japan).

\section{Blood Profile}

At the end of the experiment, 16 laying hens were randomly selected from each treatment (two hens/replication) and blood samples were taken from the jugular vein by a sterilized syringe with needle. Then, the samples were transferred to either a vacuum or $\mathrm{K}_{3}$ EDTA vacuum tube (Becton Dickinson Vacutainer Systems, FranklinLakes, NJ, USA). The blood samples were centrifuged at $2000 \times \mathrm{g}$ at $4^{\circ} \mathrm{C}$ for 15 min to separate the serum. High-density lipoprotein (HDL), low-density lipoprotein (LDL), and total cholesterol, and immunoglobulin $\mathrm{G}(\mathrm{IgG})$ concentrations in the serum were then analyzed using an automatic biochemistry blood analyzer (HITACHI747, Tokyo, Japan). Whole blood samples from the $\mathrm{K}_{3}$ EDTA vacuum tube were analyzed immediately to determine the white blood cells (WBC), red blood cells (RBC), and lymphocyte concentrations using an automatic blood analyzer (ADVIA 120, Bayer, Tarrytown, NY, USA).

\section{Cecal Microflora}

At the end of the experiment, samples of cecal contents were collected from 16 laying hens randomly selected from each treatment, then placed on ice for transportation to the laboratory, where analyses were immediately performed using the method described by Wang and Kim (2011). Onegram of pooled cecal content sample was diluted 1:9 (wt/vol) with phosphate buffer saline solution (PBS; 0.1M, pH 7.0). Then, 10 -fold serial dilutions $\left(10^{-3}\right.$ to $\left.10^{-6}\right)$ of cecal content samples were generated with PBS and placed onto MacConkey (Difco Laboratories, Detroit, MI, USA) and Lactobacillus-Rogosa agar plates (Difco Laboratories) to isolate the Escherichia coli and Lactobacillus, respectively. The Lactobacillus-Rogosa and MacConkey agar plates were then incubated for $24 \mathrm{~h}$ at $37^{\circ} \mathrm{C}$ under anaerobic and aerobic conditions, respectively. After incubation, Lactobacillus and $E$. coli colonies were counted immediately using a colony counter, and are reported as colony-forming units (CFU) $\log _{10}$ per $\mathrm{g}$. 


\section{Excreta Noxious Gas Emission}

Fresh excreta from laying hens were collected from eight cages per treatment to determine excreta noxious gas emission according to the method described by Cho et al (2008). Excreta samples $(300 \mathrm{~g})$ were stored in 2-L plastic boxes. The samples were allowed to ferment for 1 day at room temperature $\left(28^{\circ} \mathrm{C}\right)$. After the fermentation period, the gases that formed were determined using a Gastec (model GV-100) gas sampling pump (Gastec Corp., Gastec detector tube No. 3L and 3La for ammonia; No. 4LL and 4LK for hydrogen sulfide; No. 70 and 70L for total mercaptan, Gastec Corp, detector tube, Ayase, Japan) from approximately $5 \mathrm{~cm}$ above the excreta samples.

\section{Statistical Analysis}

Data were statistically analyzed via ANOVA using the GLM procedure of SAS (SAS Inst. Inc., Cary, NC) for a randomized complete block design. The linear and quadratic effects of FSE among treatments were analyzed using a contrast statement. The mean values and standard error of means (SEM) were reported. Probability values less than 0.05 were considered significant.

\section{Results}

\section{Egg Production Performance}

Laying hens fed diets supplemented with FSE during weeks 27-32 showed significant differences in egg weight compared with those fed the control treatment, as dietary FSE increased from 0.05 to $0.1 \%$ (linear, $P=0.012$ ). However, throughout the experimental period, there was no significant difference in egg production, feed intake, and feed conversion in laying hens fed different levels of FSE in their diet (Table 2).

\section{Egg Quality}

Eggshell breaking strength and eggshell thickness were found to be increased in the FSE groups compared with the control group (linear $P<0.05$ ). As the dietary levels of FSE increased, a linear increase in the intensity of yolk color was observed $(P=0.001)$. There was no significant difference in eggshell color, Haugh units, or albumen height of laying hens fed different levels of FSE in their diet (Table 3).

\section{Blood Profiles}

Serum levels of HDL-cholesterol were elevated in the FSE treatment group compared with the control group (linear, $P=$ 0.017). The total cholesterol concentration decreased as dietary FSE increased in laying hens compared with laying hens fed the control diet (linear, $P=0.042$ ). However, serum LDL-cholesterol and IgG levels were not affected by the addition of FSE. Furthermore, FSE treatment had no significant effect on WBC, RBC, or lymphocytes (Table 4).

\section{Cecal Microflora}

FSE supplementation linearly increased Lactobacillus numbers in the cecum, compared with the control treatment $(P=0.012)$. Cecal $E$. coli decreased quadratically as dietary FSE increased $(P=0.010)$ (Table 5).

\section{Excreta Noxious Gas Emissions}

Excreta ammonia emissions were decreased as dietary FSE supplementation increased (linear, $P=0.020$ ). However, FSE supplementation did not affect total mercaptan and hydrogen sulfide emissions, compared with the control treatment (Table 6).

Table 2. The effects of dietary fenugreek seed extract (FSE) on productivity in laying hens ${ }^{1}$

\begin{tabular}{|c|c|c|c|c|c|c|}
\hline & \multicolumn{3}{|c|}{ FSE, $\%$} & \multirow{2}{*}{ SEM $^{2}$} & \multicolumn{2}{|c|}{$P$-value } \\
\hline & 0 & 0.05 & 0.1 & & Linear & Quadratic \\
\hline Egg production, $\%$ & 96.0 & 97.9 & 96.5 & 1.21 & 0.677 & 0.115 \\
\hline Egg weight, g & 63.1 & 64.2 & 66.4 & 0.89 & 0.012 & 0.642 \\
\hline Feed intake, $\mathrm{g}$ & 115 & 115 & 117 & 1.93 & 0.659 & 0.698 \\
\hline Feed conversion, g:g & 1.833 & 1.797 & 1.757 & 0.02 & 0.052 & 0.952 \\
\hline
\end{tabular}

${ }^{1}$ Each treatment mean represents 8 replicates (16 hens/replicate)

${ }^{2}$ Standard error of mean

Table 3. The effects of dietary fenugreek seed extract (FSE) on egg quality in laying hens ${ }^{1}$

\begin{tabular}{|c|c|c|c|c|c|c|}
\hline & \multicolumn{3}{|c|}{ FSE, $\%$} & \multirow{2}{*}{ SEM $^{2}$} & \multicolumn{2}{|c|}{$P$-value } \\
\hline & 0 & 0.05 & 0.1 & & Linear & Quadratic \\
\hline Eggshell color & 11.25 & 11.35 & 11.3 & 0.19 & 0.855 & 0.752 \\
\hline Eggshell breaking strength, $\mathrm{kg} / \mathrm{cm}^{2}$ & 4.390 & 4.483 & 4.661 & 0.06 & 0.012 & 0.588 \\
\hline Eggshell thickness, $\mathrm{mm}^{-2}$ & 35.41 & 36.36 & 36.73 & 0.43 & 0.038 & 0.304 \\
\hline Haugh unit & 82.52 & 83.03 & 82.62 & 1.41 & 0.959 & 0.788 \\
\hline Albumen height, mm & 7.55 & 7.84 & 7.68 & 0.19 & 0.635 & 0.355 \\
\hline Yolk color & 7.0 & 7.1 & 7.8 & 0.14 & 0.001 & 0.091 \\
\hline
\end{tabular}

\footnotetext{
${ }^{1}$ Each treatment mean represents 40 replicates (5 eggs/replicate).
}

${ }^{2}$ Standard error of mean 
Table 4. The effect of dietary fenugreek seed extract (FSE) on blood profiles in laying hens ${ }^{1}$

\begin{tabular}{|c|c|c|c|c|c|c|}
\hline & \multicolumn{3}{|c|}{ FSE, $\%$} & \multirow{2}{*}{$\mathrm{SEM}^{2}$} & \multicolumn{2}{|c|}{$P$-value } \\
\hline & 0 & 0.05 & 0.1 & & Linear & Quadratic \\
\hline White blood cells, $10^{3} / \mu l$ & 27.0 & 27.3 & 31.5 & 3.92 & 0.365 & 0.636 \\
\hline Red blood cells, $10^{6} / \mu l$ & 2.3 & 2.6 & 2.3 & 0.15 & 0.906 & 0.141 \\
\hline Lymphocyte, \% & 70.4 & 60.7 & 66.2 & 9.92 & 0.745 & 0.495 \\
\hline HDL-cholesterol, mg/dL & 33 & 41 & 44 & 2.05 & 0.017 & 0.503 \\
\hline LDL-cholesterol, mg/dL & 63 & 62 & 61 & 6.24 & 0.848 & 0.987 \\
\hline Total cholesterol, $\mathrm{mg} / \mathrm{dL}$ & 222 & 172 & 184 & 11.14 & 0.042 & 0.067 \\
\hline Immunoglobulin $\mathrm{G}, \mathrm{mg} / \mathrm{dL}$ & 446 & 469 & 452 & 106.45 & 0.968 & 0.883 \\
\hline
\end{tabular}

${ }^{1}$ Each treatment mean represents 16 replicates ( 2 hens/replicate).

${ }^{2}$ Standard error of mean

Table 5. The effects of dietary fenugreek seed extract (FSE) on cecal microbiota in laying hens ${ }^{1}$

\begin{tabular}{|c|c|c|c|c|c|c|}
\hline & \multicolumn{3}{|c|}{ FSE, $\%$} & \multirow{2}{*}{$\mathrm{SEM}^{2}$} & \multicolumn{2}{|c|}{$P$-value } \\
\hline & 0 & 0.05 & 0.1 & & Linear & Quadratic \\
\hline Lactobacillus, $\log _{10} \mathrm{cfu} / \mathrm{g}$ & 6.98 & 7.33 & 7.42 & 0.10 & 0.012 & 0.298 \\
\hline E. coil, $\log _{10} \mathrm{cfu} / \mathrm{g}$ & 6.57 & 6.14 & 6.37 & 0.08 & 0.151 & 0.010 \\
\hline
\end{tabular}

${ }^{1}$ Each treatment mean represents 16 replicates (2 hens/replicate).

${ }^{2}$ Standard error of mean

Table 6. The effects of dietary fenugreek seed extract (FSE) on excreta gas emission in laying hens ${ }^{1}$

\begin{tabular}{|c|c|c|c|c|c|c|}
\hline & \multicolumn{3}{|c|}{ FSE, $\%$} & \multirow{2}{*}{$\mathrm{SEM}^{2}$} & \multicolumn{2}{|c|}{$P$-value } \\
\hline & 0 & 0.05 & 0.1 & & Linear & Quadratic \\
\hline Total mercaptan, ppm & 1.4 & 0.9 & 1.0 & 0.17 & 0.058 & 0.134 \\
\hline Ammonia, ppm & 48 & 33 & 30 & 4.40 & 0.020 & 0.277 \\
\hline Hydrogen sulfide, ppm & 2.4 & 2.4 & 2.4 & 0.07 & 0.987 & 0.892 \\
\hline
\end{tabular}

${ }^{1}$ Each treatment mean represents 8 replicates (16 hens/replicate).

${ }^{2}$ Standard error of mean

\section{Discussion}

Laying performance of the FSE-treated groups did not significantly differ over 27-32 weeks in our study. PFA has been investigated in numerous studies on poultry with varying responses, depending upon the plant species, disease challenges, and different environmental conditions used. Results have also varied depending on the specific plantderived compound used, or stress type (Demir et al., 2003; Griggs and Jacob, 2005; Cabuk et al., 2006; Cho et al., 2014). Several studies have reported that dietary supplementation with extracts of some plants increased egg production, feed conversion ratio, and egg weight in laying hens (Uuganbayar et al., 2005; Nadia et al., 2008; Radwan et al., 2008). Recent reports have also suggested an improvement in the early growth performance of broilers and pigs, when supplemented with FSE (Hossain et al., 2015; Park and Kim, 2016). In contrast, previous studies have shown that neither PFA nor FSE exhibited significant effects on feed intake, feed efficiency, and/or egg production of laying hens (Botsoglou et al., 2005; Deng et al., 2012; Al-Aqil, 2016). Growth responses of broilers, or the egg production performance of laying hens supplemented with PFA remain controversial, and the mechanism of FSE action on poultry performance has not yet been clearly established. Our finding suggests that FSE had no direct beneficial effect on egg production, feed intake, or feed conversion. However, a significant improvement in egg weight, eggshell strength, and eggshell thickness was observed when FSE was included in the diet. The results of our study were similar to those reported recently by El-Shafei et al. (2012), who showed significant effects on the eggshell thickness, eggshell weight, and specific gravity between control and fenugreek powder groups. Qureshi et al. (2016) reported that fenugreek seeds in the diet may enhance nutrient absorption due to greater villus height and crypt depth, thereby improving intestinal health. Similarly, Amad et al. (2011) found that the apparent ileal digestibility of crude ash, calcium, and phosphorus 
increased linearly with increasing dose of PFA in the diet. Moreover, fenugreek seeds naturally contain high levels of minerals, including calcium, iron, and zinc (Hooda and Jood, 2003). The beneficial effect on egg weight, eggshell breaking strength, and eggshell thickness might be attributable to favorable alterations in the intestinal environment and function, which may have increased intestinal calcium absorption. Therefore, FSE may help calcium utilization for eggshell formation, although no significant differences were observed in egg production performance between the FSE groups and the control. In our study, the addition of FSE increased the intensity of the yolk color. Fenugreek seeds are also widely used as a spice and food colorant in food preparations because of their light yellow-brown color (Ciftci et al., 2011). An increase in the intensity of yolk color is likely to be due to the action of the yellow color agent present in FSE on the yolk following the addition of FSE. Thus, FSE could be supplied as a component of pigment in the diets in order to influence egg yolk yellowness.

Serum lipid metabolites in relation to PFA and their extracts have been extensively studied. The addition of PFA could affect serum triglyceride and cholesterol concentrations and effectively prevent the progress of hypercholesterolemia and cholesterol accumulation in the liver induced by a high cholesterol diet in rats (Fukushima et al., 2001). PFA also significantly decreased blood lipid fractions and increased high-density lipoprotein in poultry (Abdel-Azeem, 2005). Results obtained in the present study show that FSE increases serum HDL-cholesterol, and decreases total cholesterol, regardless of LDL-cholesterol levels. Some studies have indicated that fenugreek seeds have hypocholesterolemic activity, which may reduce the risk of heart disease (Sharma et al., 1991; Khosla et al., 1995). Saponins, which are a major active constituent of the fenugreek seeds, have beneficial effects on blood cholesterol and triglyceride concentrations in rats, rabbits, and humans (Morehouse et al., 1999; Sowmya and Rajyalakshmi, 1999; Afrose et al., 2009). Additionally, non-starch polysaccharides, which provide the major soluble fiber content in fenugreek seeds, include galactomannan (Brummer et al., 2003), which has been reported to reduce blood lipids (Yamamoto et al., 2000; Srichamroen et al., 2001). The presence of these compounds in particular could increase the viscosity of the digested food and decrease serum total cholesterol levels by inhibiting bile salt reabsorption in the small intestine (Kumar et al. 2012). Therefore, the decreased concentration of blood lipid metabolites observed in the present study due to the inclusion of dietary FSE may be related to the saponins or galactomannan fiber content in FSE.

Several PFAs have long been recognized for their antimicrobial actions against major pathogens including coccidium and fungi (Giannenas et al., 2003; Windisch et al., 2008). An in vitro study by $\mathrm{Du}$ et al. (2015) found that carvacrol and thymol inhibited the growth of E. coli, Clostridium perfringens, and Salmonella strains. Gutierrez et al. (2008) reported that in vitro, essential oils including basil, lemon balm, marjoram, oregano, rosemary, sage, and thyme, strongly inhibited the growth of B. cereus, $P$. aeruginosa, E. coli, and L. monocytogenes. In an in vivo study, Guo et al. (2004) demonstrated that the herb extracts were largely associated with reduced cecal Bacteroides spp., enterococci, and $E$. coli numbers, but increased numbers of bifidobacteria and lactobacilli, relative to the control and antibiotic groups in chickens. In addition, Zentek et al. (2013) noted that a fenugreek diet caused higher Lactobacillus and Clostridium concentrations and lower Escherichia, Hafnia, and Shigella concentrations in the small intestine of piglets. Many investigators have reported an antibacterial effect of fenugreek seeds (Dash et al., 2011; Alwhibi and Soliman, 2014; Majumdar and Alluri, 2014). Such an effect seems to be related to the presence of certain molecular compounds, usually in the form of secondary metabolites, such as flavonoids, saponins, and phenolic compounds (Dash et al., 2011). In our study, laying hens fed the FSE diets had a higher population of cecal Lactobacillus and a lower population of E. coli. Therefore, decreased cecal $E$. coli counts in laying hens fed dietary FSE may be explained by the antibacterial activity of FSE against different pathogenic bacteria. These effects of FSE on cecal microflora have led to a reduction in ammonia gas emission in laying hen excreta. In other words, a positive effect of FSE is exerted by suppressing harmful cecal E. coli, and favoring beneficial Lactobacillus, which may be reflected in the ammonia gas emissions of the excreta. This result is in line with the reports of Ushild et al. (2002) and Sung (2013), who determined that supplemental PFA decreased noxious gas emission, including ammonia concentrations, in pigs and laying hens. Furthermore, decreased levels of excreta ammonia gas found in the FSE groups may be associated with intestinal pH. Denli et al. (2004) observed that supplementation of quail diets with PFA (thyme and black seed essential oils) significantly decreased intestinal $\mathrm{pH}$. Similarly, Zentek et al. (2013) indicated that fenugreek seed reduced the $\mathrm{pH}$ in the cecum and colon of piglets, due to an increase in the number of lactate-producing bacteria or their relevant metabolic activity. Therefore, the decrease in ammonia gas emission observed in excreta following the addition of FSE to laying hen diets is thought to be induced by the maintenance of beneficial microbiota or a reduction in intestinal $\mathrm{pH}$.

In conclusion, based on these findings, FSEs are a valuable natural feed additive for laying hens, particularly with regard to egg weight, egg quality, serum cholesterol, cecal lactobacilli number and excreta ammonia gas emission.

\section{References}

Abdel-Azeem FA. Green tea flowers (Camellia sinensis) as natural anti-oxidants feed additives in growing Japanese quail diets. Egyptian Poultry Science Journal, 25: 569-588. 2005.

Afrose S, Hossain MS, Maki T and Tsujii H. Karaya root saponin exerts a hypocholesterolemic response in rats fed a highcholesterol diet. Nutrition Research, 29: 350-354. 2009.

Al-Aqil AAA. Effects of adding dietary fenugreek (Trigonella foenum-graecum L.) powder on productive performance and 
egg quality of laying hens. International Journal of Poultry Science, 15: 259-263. 2016.

Alwhibi MS and Soliman DA. Evaluating the antibacterial activity of fenugreek (Trigonella foenum-graecum) seed extract against a selection of different pathogenic bacteria. Journal of Pure and Applied Microbiology, 8: 817-821. 2014.

Amad AA, Manner K, Wendler KR, Neumann K and Zentek J. Effects of a phytogenic feed additive on growth performance and ileal nutrient digestibility in broiler chickens. Poultry Science, 90: 2811-2816. 2011.

Amouzmehr A, Dastar B, Nejad JG, Sung KI, Lohakare J and Forghani F. Effect of garlic and thyme extracts on growth performance and carcass characteristics of broiler chicks. Journal of Animal Science and Technology, 54: 185-190. 2012.

Bash E, Ulbricht C, Kuo G, Szapary P and Smith M. Therapeutic applications of fenugreek. Alternative Medicine Review, 8: 20-27. 2003.

Botsoglou N, Florou-Paneri P, Botsoglou E, Dotas V, Giannenas I, Koidis A and Mitrakos P. The effect of feeding rosemary, oregano, saffron and $\alpha$-tocopheryl acetate on hen performance and oxidative stability of eggs. South African Journal of Animal Science, 35: 143-151. 2005.

Brummer Y, Cui W and Wang Q. Extraction, purification and physicochemical characterization of fenugreek gum. Food Hydrocolloids, 17: 229-236. 2003.

Çabuk M, Bozkurt M, Alçiçek A, Çatli AU and Başer KHC. Effect of a dietary essential oil mixture on performance of laying hens in the summer season. South African Journal of Animal Science, 36: 215-221. 2006.

Cho JH, Chen YJ, Min BJ, Yoo JS, Wang Y and Kim IH. Effects of reducing dietary crude protein on growth performance, odor gas emission from manure and blood urea nitrogen and IGF-1 concentrations of serum in nursery pigs. Animal Science Journal, 79: 453-459. 2008.

Cho JH, Kim HJ and Kim IH. Effects of phytogenic feed additive on growth performance, digestibility, blood metabolites, intestinal microbiota, meat color and relative organ weight after oral challenge with Clostridium perfringens in broilers. Livestock Science, 160: 82-88. 2014.

Ciftci ON, Przybylski R, Rudzinska M and Acharya S. Characterization of fenugreek (Trigonella foenum-graecum) seed lipids. Journal of the American Oil Chemists' Society, 88: 1603-1610. 2011.

Dash BK, Sultana S and Sultana N. Antibacterial activities of methanol and acetone extracts of fenugreek (Trigonella foenum) and coriander (Coriandrum sativum). Life Sciences and Medicine Research, 27: 65-72. 2011.

Demir E, Sarica S, Ozcan MA and Suicmez M. The use of natural feed additives as alternatives for an antibiotic growth promoter in broiler diets. British Poultry Science, 44: S44-S45. 2003.

Deng W, Dong XF, Tong JM, Xie TH and Zhang Q. Effects of an aqueous alfalfa extract on production performance, egg quality and lipid metabolism of laying hens. Journal of Animal Physiology and Animal Nutrition, 96: 85-94. 2012.

Denli M, Okan F and Uluocak AN. Effect of dietary supplementation of herb essentail oils on the growth performance, carcass and intestinal characteristics of quail (Coturnix coturnix japonica). South African Journal of Animal Science, 34: 174179. 2004.

Du E, Gan L, Li Z, Wang W, Liu D and Guo Y. In vitro antibacterial activity of thymol and carvacrol and their effects on broiler chickens challenged with Clostridium perfringens. Journal of
Animal Science and Biotechnology, 6: 58-69. 2015.

El-Shafei AA, Hassan MSH and Al-Gamal MA. Influence of fenugreek and copper sulfate levels in the diet on physiological and productive performance of laying Japanese quail. Egyptian Poultry Science Journal, 32: 909-930. 2012.

Fukushima M, Ohashi T, Fujiwara Y, Sonoyama K and Nakano M. Cholesterol-lowering effects of maitake (Grifola frondosa) fiber, shiitake (Lentinus edodes) fiber, and enokitake (Flammulina velutipes) fiber in rats. Experimental Biology and Medicine, 226: 758-765. 2001.

Giannenas I, Florou-Paneri P, Papazahariadou M, Christaki F, Botsoglou NA and Spais AB. Effect of dietary supplementation with oregano essential oil on performance of broilers after experimental infection with Eimeria tenella. Archives of Animal Nutrition, 57: 99-106. 2003.

Griggs JP and Jacob JP. Alternatives to antibiotics for organic poultry production. Journal of Applied Poultry Research, 14: 750-756. 2005.

Guo FC, Williams BA, Kwakkel RP, Li HS, Li XP, Luo JY, Li WK and Verstegen MWA. Effect of mushroom and herb polysaccharides, as alternative for antibiotics, on the cecal microbial ecosystem in broiler chickens. Poultry Science, 83: 175-182. 2004.

Gutierrez J, Barry-Ryan C and Bourke P. The antimicrobial efficacy of plant essential oil combinations and interactions with food ingredients. International Journal of Food Microbiology, 124: 91-97. 2008.

Hashemi SR, Zulkifli I, Hair-Bejo M, Farida A and Somchit MN. Acute toxicity study and phytochemical screening of selected herbal aqueous extract in broiler chickens. International Journal of pharmacology, 4: 352-360. 2008.

Hernandez F, Madrid J, Garcia V, Orengo J and Megias MD. Influence of two plant extracts on broilers performance, digestibility, and digestive organ size. Poultry Science, 83: 169-174. 2004.

Hooda S and Jood S. Effect of soaking and germination on nutrient and antinutrient contents of fenugreek (Trigonella foenum graecum L.). Journal of Food Biochemistry, 27: 165-176. 2003.

Hossain MM, Begum M, Nyachoti CM, Hancock JD and Kim IH. Dietary fenugreek seed extract improves performance and reduces fecal E. coli counts and fecal gas emission in lactating sows and suckling piglets. Canadian Journal of Animal Science, 95: 561-568. 2015.

Kaviarasan S, Naik GH, Gangabhagirathi R, Anuradha CV and Priyadarsini KI. In vitro studies on antiradical and antioxidant activities of fenugreek (Trigonella foenumgraceum) seeds. Food Chemistry, 103: 31-37. 2007.

Khalaji S, Zaghari M, Hatami KH, Hedari-Dastjerdi S, Lotfi L and Nazarian H. Black cumin seeds, Artemisia leaves (Artemisia sieberi), and Camellia L. plant extract as phytogenic products in broiler diets and their effects on performance, blood constituents, immunity, and cecal microbial population. Poultry Science, 90: 2500-2510. 2011.

Khosla P, Gupta DD and Nagpal PK. Effect of Trigonella foenum graecum (fenugreek) on serum lipids in normal and diabetic rats. Indian Journal of Pharmacology, 27: 89-93. 1995.

Kumar V, Sinha AK, Makkar HP, de Boeck G and Becker K. Dietary roles of non-starch polysaccharides in human nutrition: a review. Critical Reviews in Food Science and Nutrition, 52: 899-935. 2012.

Majumdar M and Alluri N. Phytochemical analysis and in vitro 
antimicrobial activity of Calotropis gigantea, Lawsonia inermis and Trigonella foecum-graecum. International Journal of Pharmacy and Pharmaceutical Sciences, 6: 524-527. 2014.

Morehouse LA, Bangerter FW, DeNinno MP, Inskeep PB, McCarthy PA, Pettini JL, Savoy YE, Sugarman ED, Wilkins RW, Wilson TC, Woody HA, Zaccaro LM and Chandler CE. Comparison of synthetic saponin cholesterol absorption inhibitors in rabbits: evidence for a non-stoichiometric, intestinal mechanism of action. Journal of lipid Research, 40: 464-474. 1999.

Nadia RL, Hassan RA, Qota EM and Fayek HM. Effect of natural antioxidant on oxidative stability of eggs and productive and reproductive performance of laying hens. International Journal of Poultry Science, 7: 134-150. 2008.

NRC. National Research Council. Nutrient Requirements of Poultry. 9th 371 rev. ed. National Academy Press, Washington, USA. 1994.

Park JH, Kang SN, Chu GM and Jin SK. Growth performance, blood cell profiles, and meat quality properties of broilers fed with Saposhnikovia divaricata, Lonicera japonica, and Chelidonium majus extracts. Livestock Science, 165: 87-94. 2014.

Park JH, Kang SN, Shin D and Shim KS. Antioxidant enzyme activity and meat quality of meat type ducks fed with dried oregano (Origanum vulgare L.) powder. Asian-Australasian Journal of Animal Science, 28: 79-85. 2015.

Park JH and Kim IH. Interactive effects of fenugreek (Trigonella foenum-graecum L.) seed extract supplementation and dietary metabolisable energy levels on the growth performance, total tract digestibility, blood profiles, and excreta gas emission in broiler chickens. Animal Production Science, 56: 1677-1682. 2016.

Qureshi S, Banday MT, Shakeel I, Adil S, Mir MS, Beigh YA and Amin U. Histomorphological studies of broiler chicken fed diets supplemented with either raw or enzyme treated dandelion leaves and fenugreek seeds. Veterinary World, 9: 269275. 2016

Radwan NL, Hassan RA, Qota EM and Fayek HM. Effect of natural antioxidant on oxidative stability of eggs and productive and reproductive performance of laying hens. International Journal of Poultry Science, 7: 134-150. 2008.

Sharma R, Raghuram T and Dayasagar R. Hypolipidaemic effect of fenugreek seeds. A clinical study. Phytotheraphy Research, 5: 145-147. 1991.

Sowmya P and Rajyalakshmi P. Hypocholesterolemic effect of germinated fenugreek seeds in human subjects. Plant Foods for Human Nutrition, 53: 359-365. 1999.

Srichamroen A, Field CJ, Thomson AB and Basu TK. The modi- fying effects of galactomannan from Canadian-grown fenugreek (Trigonella foenum-graecum L.) on the glycemic and lipidemic status in rats. Journal of Clinical Biochemistry and Nutrition, 43: 167-174. 2008.

Sung HG. Effects of fermented phytogenics on fecal odour and performance in laying hens. Annals of Animal Resource Sciences, 24: 29-37. 2013.

Udayasekhara RP and Sharma RD. An evaluation of protein quality of fenugreek seeds (Trigonella foenum graecum) and their supplementary effects. Food Chemistry, 24: 1-9. 1987.

Ushild K, Maekawa $\mathrm{M}$ and Arakawa T. Influence of dietary supplementation of herb extracts on volatile sulfur production in pig large intestine. Journal of Nutritional Science and Vitaminology, 48: 18-27. 2002.

Uuganbayar D, Bae IH, Choi KS, Shin IS, Firman JD and Yang CJ. Effects of green tea powder on laying performance and egg quality in laying hens. Asian-Australasian Journal of Animal Science, 18: 1769-1774. 2005.

Vats V, Grover JK and Rathi SS. Evaluation of anti-hyperglycemic and hypoglycemic effect of Trigonella foenum-graecum Linn, Ocimum sanctum Linn and Pterocarpus marsupium Linn in normal and alloxanized diabetic rats. Journal of Ethnopharmacology, 79: 95-100. 2002.

Vyas S, Agrawal RP, Solanki P and Trivedi P. Analgesic and antiinflammatory activities of Trigonella foenum-graecum (seed) extract. Acta Poloniae Pharmaceutica, 65: 473-476. 2008.

Wang JP and Kim IH. Effect of caprylic acid and Yucca schidigera extract on production performance, egg quality, blood characteristics, and excreta microflora in laying hens. British Poultry Science, 52: 711-717. 2011.

Windisch W, Schedle K, Plitzner C and Kroismayr A. Use of phytogenic products as feed additives for swine and poultry. Journal of Animal Science, 86: E140-E148. 2008.

Yamamoto Y, Sogawa I, Nishina A, Saeki S, Ichikawa N and Iibata S. Improved hypolipidemic effects of xanthan gum-galactomannan mixtures in rats. Bioscience Biotechnology and Biochemistry, 64: 2165-2171. 2000.

Yan L, Meng QW and Kim IH. The effect of an herb extract mixture on growth performance, nutrient digestibility, blood characteristics and fecal noxious gas content in growing pigs. Livestock Science, 141: 143-147. 2011.

Zentek J, Gärtner S, Tedin L, Männer K, Mader A and Vahjen W. Fenugreek seed affects intestinal microbiota and immunological variables in piglets after weaning. British Journal of Nutrition, 109: 859-866. 2013. 